\title{
La halitosis: revisión de la literatura. Primera parte
}

\author{
Foglio Bonda PL, Rocchetti V, Migliario M, Giannoni M*
}

\section{RESUMEN}

La halitosis es un trastorno capaz de condicionar la calidad de vida, particularmente en lo que atañe a las relaciones sociales. Mediante una atenta revisión de la literatura se han puesto de relieve las hipótesis etiológicas, tanto orales como extraorales, de la halitosis y el correspondiente enfoque diagnóstico-terapéutico por parte del odontólogo y del higienista dental.

Palabras clave: Halitosis, higiene oral, diagnóstico y tratamiento.

\section{SUMMARY}

Halitosis is a problem that may affect the quality of life, social relations in particular. Through a careful literature review, aetiological hypotheses, both oral and extraoral, on halitosis are highlighted as well as the dianostic and therapeutic approach that should be adopted by the dentist and the dental hygienist.

Key words: Halitosis, oral-hygiene, diagnosis and treatmet.

Fecha de recepción: Junio 2007.

Aceptado para publicación: Julio 2007.

Universidad del Piamonte Oriental, Licenciatura en Higiene Dental, Presidente: Prof. P. L. Foglio Bonda.

* $\quad$ Universidad de L'Aquila, Licenciatura en Higiene Dental, Presidente: Prof. M. Giannoni.

Publicado en DOCTOR OS 2007, núm. 4; Traducido por Pablo Herrera Hernández.

Foglio Bonda PL, Rocchetti V, Migliario M, Giannoni M. La halitosis: revisión de la literatura. Primera parte. Av. Odontoestomatol 2007; 23 (6): 375-386.

\section{INTRODUCCIÓN}

Con los términos halitosis, foetor ex ore o, más generalmente, mal aliento, se indica el olor desagradable del aire emitido por la cavidad oral, un trastorno que puede afectar a individuos de uno u otro sexo $\mathrm{y}$ de todas las edades.

La halitosis puede manifestarse transitoriamente como característica parafisiológica correlacionada con algunos momentos o situaciones de la vida diaria o bien ser persistente y/o patológica y estar provocada por afecciones bucales o sistémicas (1) (tabla 1).
Aunque hasta la fecha no se dispone de datos acerca de la prevalencia real de la halitosis, debido principalmente a la dificultad que entraña su evaluación objetiva, varios estudios han intentado evaluar dicha prevalencia en grupos representativos de la población general $(1,2)$.

Un estudio realizado en el Japón por Miyazaki y colaboradores ha puesto de relieve que el $25 \%$ de la población examinada presentaba un olor desagradable del aliento (3); en los Estados Unidos, el $24 \%$ de los sujetos de más de 60 años de edad declara haber sido objeto de observaciones desagradables acerca de su aliento $(1,2,4)$, y en el Canadá el $1 \%$ de la 


\section{TABLA 1.- CLASIFICACIÓN Y DESCRIPCIÓN DE LA HALITOSIS.}

\section{AdAPTADA DE: SANZ M. Roldan S. HERRERA D. Fundamentals OF BREATH MALOdOUR. J. CoNTEMP DENT PRACT 2001;4(2):1-17.}

\section{Halitosis verdadera}

1a. Halitosis fisiológica

1b. Halitosis patológica

I. Oral

II. Extraoral

Percepción de un olor desagradable, con intensidad superior a los niveles socialmente aceptables.

1. Originada por los procesos putrefactivos de la cavidad oral. Ausencia de enfermedades específicas o de condiciones patológicas que puedan causar halitosis.

2. Originada principalmente por el dorso posterior de la lengua.

3. Halitosis temporal debida a factores dietéticos.

I. Oral

1. Debida a enfermedades, condiciones patológicas o alteraciones de los tejidos bucales.

2. Debida a modificación del cubrimiento lingual por condiciones patológicas.

1. Con origen en las regiones nasales, paranasales y/o laríngeas.

2. Con origen en las vías aéreas o en el aparato digestivo superior.

3. Con origen en desórdenes sistémicos con olores transportados por vía hemática y emitidos por vía aérea (diabetes, cirrosis hepática, uremia...).

2. Pseudohalitosis

1. Halitosis no evidente, pero evidenciada por el paciente.

2. Mal olor no percibido por otros, si bien acusado por el paciente.

3. Halitofobia

Tras el tratamiento de la halitosis verdadera o de la pseudohalitosis, el paciente sigue creyéndose aquejado de halitosis.

población adulta se preocupa por los efectos que el mal aliento puede causar en la propia vida de relación (5).

Una investigación sueca (6) sobre la presencia de enfermedad periodontal en jóvenes adultos (30-40 años) residentes en el área de Estocolmo ha detectado que el $2,4 \%$ de dichos sujetos exhalaba un aliento desagradable.

En un cuestionario cumplimentado por 4.800 individuos escogidos como representativos de la población francesa, el $22 \%$ ha respondido que padece halitosis. Se trata, con todo, de una prevalencia posiblemente sobrestimada (4).

Según una investigación llevada a cabo por la Asociación Dental Estadounidense (ADA) en 1995, el
4\% de los odontólogos estadounidenses visita cada semana a seis o más pacientes con halitosis crónica $(1,4,7)$, si bien la entidad de este problema en los Estados Unidos no está lo suficientemente documentada (4).

Tal y como se indica en la tabla 1 , la halitosis puede clasificarse en:

- Halitosis verdadera, que puede dividirse en halitosis fisiológica y halitosis patológica, cuando el observador percibe un olor desagradable;

- Pseudohalitosis, cuando el mal olor es acusado por el paciente pero no es perceptible por parte del observador;

- Halitofobia, cuando, una vez eliminadas las causas y solucionado el problema, el paciente persiste en considerarse aquejado de halitosis. 
Una distinción adicional, extremadamente útil para los odontólogos y los higienistas dentales, es la que distingue la halitosis con arreglo a la sede en la que se generan los compuestos volátiles responsables del mal olor: así se distinguirá una halitosis de origen oral y otra de origen extraoral.

\section{HALITOSIS DE ORIGEN ORAL}

Las causas más frecuentes de halitosis pueden reconducirse a trastornos y eventos fisiológicos, parafisiológicos o patológicos de origen oral: en efecto, tal y como demuestra la bibliografía, en el 80-90\% de los pacientes con mal aliento el olor se origina en la boca $(1,2,4,5,8,9,10,11,12,13,14,15,16$, $17,18,19,20)$. Experimentos in vitro han demostrado que muchas bacterias orales presentes en la saliva, en la placa y en las fisuras del dorso de la lengua $(2,4,8,13,15,18,21,22,23)$ pueden producir gases que contribuyen a la compleja mezcla de moléculas olorosas detectadas en el aire espirado (4).

In vivo, los mismos microorganismos degradan los péptidos que contienen azufre y los aminoácidos contenidos en la saliva, en el fluido crevicular, en el suero, en los restos de comida, en las células epiteliales exfoliadas y en las células corpusculares de la sangre $(1,4,11,22,24)$, produciendo:

- Compuestos volátiles de sulfuro (CVS), particularmente sulfuro de hidrógeno, metilmercaptano y sulfuro de dimetilo $(1,2,4,9,10,13,14,15$, $18,21,22,24,25,26)$;

- Ácidos grasos de cadena corta como el ácido butírico, el ácido valérico, el ácido isovalérico y el ácido propiónico;

- Compuestos diamínicos, poliamínicos e indólicos como el escatol, la metilamina, la putrescina y la cadaverina $(1,4,12,18,21,26)$.

Estos gases, que se volatilizan en el medio ambiente oral, son recogidos y transportados fuera de la boca durante los actos espiratorios y la fonación, dando lugar al foetor ex ore (1).

El sulfuro de hidrógeno y el metilmercaptano constituyen aproximadamente el $90 \%$ de los compuestos volátiles de sulfuro detectables en el aire espirado, y son los responsables principales de la producción de mal olor $(4,9,11)$.

El sulfuro de hidrógeno lo produce principalmente el tercio posterior de la lengua, mientras que el metilmercaptano y el sulfuro de dimetilo los generan principalmente los tejidos periodontales $(15,28,29)$.

Sin embargo, resulta difícil identificar todas las sustancias malolientes implicadas, debido al gran número de compuestos producidos por las bacterias orales: en un estudio realizado sobre muestras de saliva y cubrimiento lingual incubadas durante 24 horas se han aislado más de 85 compuestos volátiles orgánicos pertenecientes a siete grupos químicos (4) (tabla 2).

Incubando muestras de cubrimiento lingual con caseína también se ha evaluado el aumento de algunos compuestos y la aparición de nuevos; dicho experimento ha sugerido que la producción de compuestos malolientes es dinámica y cambia como respuesta a las fuentes nutritivas.

Un estudio de Kleinberg y colaboradores (25) ha puesto de relieve que los sustratos que más favore-

TABLA 2.- LISTA DE COMPUESTOS VOLÁTILES ORGÁNICOS PRODUCIDOS A PARTIR DE SALIVA Y CUBRIMIENTO LINGUAL. ADAPTADA DE: LOESCHE WJ, KAZOR C. MICROBIOLOGY AND TREATMENT OF HALITOSIS. PERIODONTOL 2000; 28: 256-79.

1. Compuestos sulfurados: $\mathrm{H}_{2} \mathrm{~S}, \mathrm{CH}_{3} \mathrm{SH}$.

2. Ácidos grasos de cadena corta: Propiónico, butírico, valérico.

3. Poliaminas: Cadaverina, putrescina.

4. Alcohol.

5. Compuestos fenólicos: Indol, escatol, piridina

6. Compuestos alcalinos: 2-metilpropano

7. Cetonas.

8. Compuestos que contienen nitrógeno: Urea, amoniaco.

Compuestos desconocidos $n=34$ 
cen la generación de mal olor son el triptófano, la ornitina y los aminoácidos que contienen azufre. Pero el descubrimiento más interesante realizado por Kleinberg fue que la producción de moléculas malolientes se veía inhibida por el ambiente ácido que se creaba al añadir azúcar al sustrato $(1,4)$. Los autores explicaron este dato por la rapidez con que la glucosa es fermentada por la flora sacarolítica (como estreptococos y actinomicetos), que constituye la población dominante de los microorganismos salivales (4). En efecto, dicha fermentación rebaja los niveles de $\mathrm{pH}$, inhibiendo la actividad metabólica de numerosos microorganismos proteolíticos $(4,25)$. Además, la disponibilidad de glucosa en exceso determina, en algunas especies bacterianas que pueden fermentar tanto péptidos como hidratos de carbono (Fusobacterium nucleatum y Prevotella intermedia), el uso preferencial de estos últimos en caso de que ambos sustratos estén disponibles en abundancia. Por ejemplo, la enzima similar a la tripsina del Stomatococcus mucilaginosus, especie presente en la lengua, es reprimida por la glucosa, lo que sugiere que in vivo, en ausencia de glucosa o sacarosa, esta enzima se expresa plenamente, por lo que es capaz de degradar los péptidos salivales responsables de la producción de compuestos malolientes (4).

Existen varias vías metabólicas bacterianas capaces de dar origen a CVS a nivel bucal: entre ellas se se- ñalan principalmente las reacciones reductoras de los sulfatos y el catabolismo de los aminoácidos que contienen azufre (metionina, cisteína, cistina, triptófano, lisina), derivados de la actividad proteolítica de la microbiota oral $(1,2,25)$. El metabolismo bacteriano de estos sustratos se realiza en condiciones de anaerobiosis, y se ve favorecido por condiciones de basicidad $(\mathrm{pH}=7,2)$ del medio ambiente oral.

No existe un agente etiológico concreto entre las más de trescientas bacterias orales que pueden causar halitosis (30); sin embargo, las bacterias principalmente implicadas en la producción de mal olor son gramnegativas, como es el caso de Fusobacterium, Veillonella, T. denticola, $P$. gingivalis, Bacteroides, Centipeda, Selenomonas, Klebsiella pneumoniae y Peptostreptococcus, mientras que la contribución de bacterias grampositivas es menor (31) (tabla 3).

Las diferentes especies de Eubacterium (grampositivas anaerobias), Selenomonas, Centipeda, Bacteroides y Peptostreptococcus (gramnegativas anaerobias) se han revelado particularmente activas por su capacidad de producir sulfuro de hidrógeno a partir de la cisteína, mientras que algunas especies de Fusobacterium, Bacteroides, Porphyromonas (gramnegativas anaerobias) y Eubacterium pueden producir metilmercaptano a partir de la metionina (1).

\section{TABLA 3.- MICROORGANISMOS MÁS ACTIVOS EN LA PRODUCCIÓN DE CVS IN VITRO. ADAPTADA DE: LOESCHE WJ, KAZOR C. MICROBIOLOGY AND TREATMENT OF HALITOSIS. PERIODONTOL 2000; 28: 256-79.}

$\mathrm{H}_{2} \mathrm{~S}$ a partir de cisteína

- Peptostreptococcus anærobius

- Micron prevotii

- Eubacterium limosum

- Bacteroides spp

- Centipeda periodontii

- Selenomonas artemidis

$\mathrm{H}_{2} \mathrm{~S}$ a partir de suero

- Prevotella intermedia

- Prevotella loescheii

- Porphyromonas gingivalis

- Treponema denticola
$\mathrm{CH}_{3} \mathrm{SH}$ a partir de metionina

- Fusobacterium nucleatum

- Fusobacterium periodonticum

- Eubacterium

- Bacteroides spp
$\mathrm{CH}_{3} \mathrm{SH}$ a partir de suero

- Treponema denticola

- Porphyromonas gingivalis 
En conclusión, las bacterias gramnegativas anaerobias parecen ser las mayores responsables de la producción de CVS, que liberan por putrefacción de compuestos peptídicos sulfurados $(2,14,17,25)$ (tabla 4).

\section{Cubrimiento lingual}

La superficie dorsal de la lengua está revestida de una mucosa especializada, diferenciada en extroflexiones epitelio-conectivas que constituyen las papilas gustativas filiformes y fungiformes.

Dichas extroflexiones tienen la principal función de incrementar la superficie disponible para favorecer el contacto responsable de la sensibilidad gustativa y propioceptiva (1) (figs. 1 y 2).

Las poblaciones bacterianas que colonizan la lengua, junto con las células superficiales exfoliadas y los restos alimenticios, forman un cubrimiento cuyo espesor varía en las diferentes zonas del dorso lingual, según los períodos del día y conforme

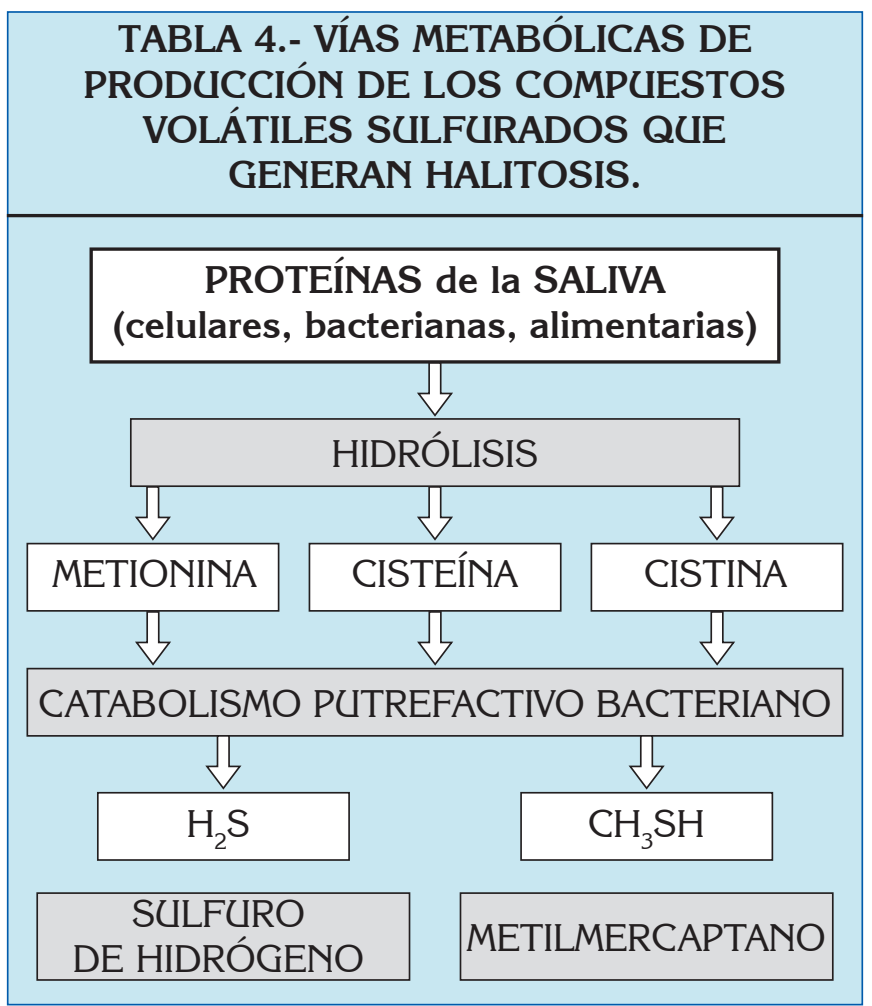

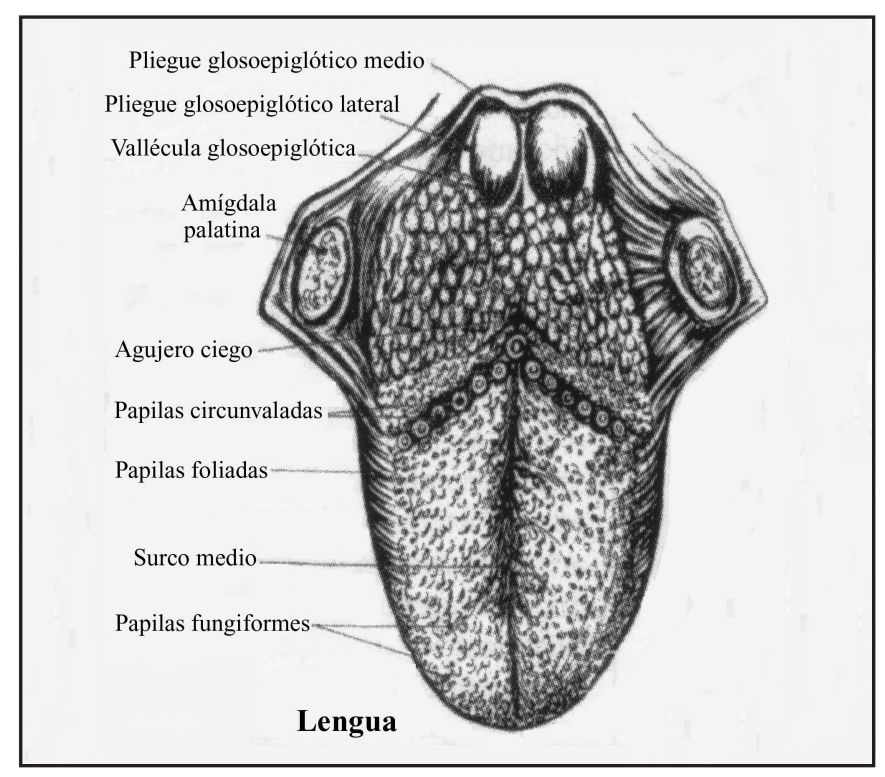

Fig. 1. Lengua (www.pavatools.it).

a la mayor o menor actividad funcional, así como con arreglo al nivel de la higiene oral individual (1) (fig. 3).

La acumulación de placa es mayor en el tercio posterior de la lengua, ya que éste, diferentemente de los dos tercios anteriores, que están en constante fricción con los dientes (32) y con el paladar duro, entra en contacto con el paladar blando, el cual, al carecer de arrugas palatinas, no puede desarrollar una acción eficaz de limpieza (30) (fig. 4).

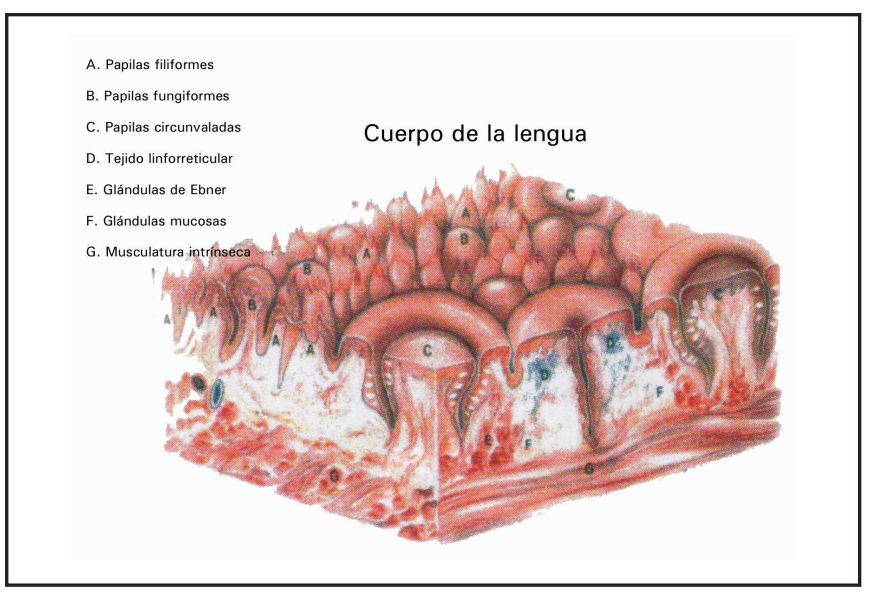

Fig. 2. Mucosa de la lengua (www.pavatools.it) 


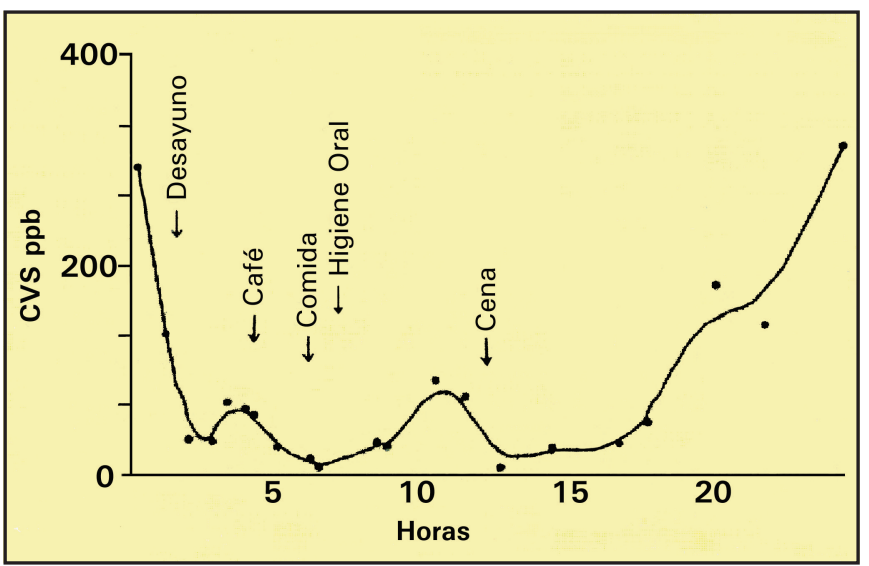

Fig. 3. Concentración de CVS en el aire espirado en función del tiempo y de diferentes actividades diarias (Rosemberg y McCulloch 1992).

Como confirman varios autores $(4,21,28,33,34$, 35), la mayor producción de CVS se genera a partir del dorso de la lengua, especialmente desde su tercio posterior, y ello tanto en sujetos con buena salud oral como en los aquejados de gingivitis y periodontitis $(1,4)$. En cambio, la contribución de la placa subgingival a la génesis del mal olor es menos relevante: en efecto, el área del dorso lingual está mucho más expuesta a la atmósfera gaseosa presente en la cavidad oral que la placa, confinada en bolsas que se caracterizan por su escaso intercambio gaseoso $(\mathrm{PO} 2=2 \%)(4)$.

Por otro lado, resulta patente que la disponibilidad de restos alimenticios y de nutrientes contenidos en

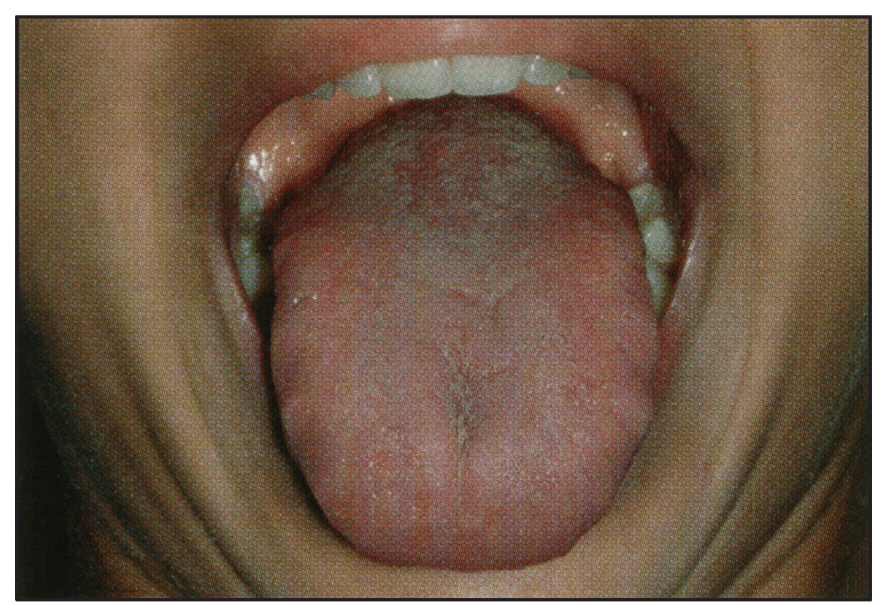

Fig. 4. Cubrimiento lingual. la saliva se ve enormemente facilitada por la flora retenida en la superficie lingual, a diferencia de cuanto acontece con la presente en las bolsas periodontales. En efecto, la microflora lingual se ve humidificada por más de un litro de saliva diario, mientras que sólo $1 \mathrm{mg}$ de fluido crevicular humidifica toda la placa subgingival.

Estas consideraciones pueden explicar por qué, si bien un tercio de los pacientes con periodontopatía presentan halitosis, ésta guarda relación con la presencia de placa en el dorso lingual y no con la enfermedad periodontal en sí (32).

En efecto, al medir los niveles de CVS en pacientes con periodontopatía se ha detectado que dichos niveles superaban significativamente (4 veces) los de los sujetos sanos, pero también se ha comprobado que su cantidad de cubrimiento lingual era seis veces más consistente que la de los sujetos sanos (90 mg y $14 \mathrm{mg}$ respectivamente). Estos 90 mg superaban en peso toda la cantidad de placa presente en las bolsas gingivales, ya que asumiendo que una bolsa de $6 \mathrm{~mm}$ contenga aproximadamente $1 \mathrm{mg}$ de placa, se necesitarían 90 bolsas periodontales para obtener un número equivalente de bacterias (28).

\section{Microflora de la lengua}

Aunque, tal y como queda afirmado, las bacterias que colonizan la lengua son las mayores responsables de la producción de mal olor, muy poco es lo que se sabe acerca de la composición de la población bacteriana de la lengua (4).

En efecto, debido a las complejas técnicas de identificación y crecimiento in vitro y a la posibilidad de recoger sólo porcentajes bajos de microorganismos, la mayor parte de las bacterias presentes en el dorso lingual están aún pendientes de identificación (35).

Hasta el año 2000, bacterias como Veillonella parvula, Streptococcus intermedius, Actinomyces odontolyticus y Clostridium innocuum constituían el $74 \%$ de los microorganismos identificados, pero sólo resultaba posible cultivar el $22 \%$ de las bacterias presentes en muestras de cubrimiento lingual (4). 
Una investigación recientemente publicada por Kazor y colaboradores en el Journal of Clinical Microbiology (35) arroja nuevos datos: dichos investigadores han empleado técnicas de secuenciación genética con vistas a identificar las bacterias presentes en el dorso lingual en pacientes con halitosis y sin ella. El descubrimiento más notable ha sido que el mal aliento está asociado a la falta de tres cepas muy extendidas en las bocas de quienes no padecen halitosis; por el contrario, en la cavidad oral de pacientes con foetor ex ore prolifera una cantidad de bacterias desconocidas hasta la fecha.

En total, han salido a la luz noventa y dos especies bacterianas distintas, de las que sólo treinta y ocho ya se conocían. Además, veintinueve especies se han revelado características de la lengua, toda vez que nunca se habían aislado hasta ahora en muestras de placa y fluido crevicular tanto en sujetos sanos como en pacientes con periodontitis o gingivitis ulcerativa necrosante aguda (GUNA).

Las bacterias "buenas", presentes en ausencia de halitosis, son Streptococcus salivaris, Rothia mucillaginosa y algunas especies aún no identificadas de Eubacterium; en concreto, Streptococcus salivaris resulta ser la especie predominante en sujetos sin halitosis y típicamente ausente en sujetos con halitosis.

Las especies recientemente identificadas, que se añaden a las ya conocidas y más asociadas a la halitosis, son, en cambio, Atopobium parvulum, Eubacterium sulci, Solobacterium moorei, junto con algunas cepas de Dialister y Streptococcus aún pendientes de identificación (35).

Estos resultados, amén de brindar nuevas ocasiones de investigación e identificación de las especies bacterianas implicadas en la producción de mal olor, confirman la extraordinaria biodiversidad de la cavidad oral, que se revela como un hábitat riquísimo, con más de 600 especies conocidas y muchas otras aún por identificar.

\section{Saliva}

La saliva desempeña funciones tan variadas como contrapuestas entre los mecanismos de desarrollo de la halitosis: por un lado, desarrolla una acción protectora al inhibir el crecimiento de los microorganismos anaerobios mediante la aportación de oxígeno a las biopelículas bucales (56), actuando como solvente de los compuestos volátiles y facilitando el alejamiento mecánico de los restos alimenticios y de los detritus celulares; por otro lado, transporta al interior de dichas biopelículas los nutrientes que, metabolizados por la microbiota oral, generan el mal olor $(1,30,36)$.

Por consiguiente, cuando el flujo salival resulta abundante se da una mayor aportación de oxígeno a los tejidos orales y un mayor alejamiento mecánico de los restos alimenticios y de los detritus celulares; cuando, por el contrario, la cantidad de saliva resulta escasa, prevalecen las condiciones que favorecen el desarrollo del mal aliento. Con todo, los datos de algunos estudios clínicos $(33,37)$ no han detectado niveles mayores de halitosis en pacientes con xerostomía. Una explicación plausible es que la producción de compuestos malolientes tenga su origen principalmente en un ambiente alcalino, mientras que la saliva de pacientes aquejados de xerostomía es con frecuencia ácida (8).

Las consideraciones anteriormente apuntadas sobre la función de la saliva explican los niveles variables de halitosis, de origen oral y susceptible de considerarse fisiológica o parafisiológica, que pueden manifestarse en todos los sujetos en buenas condiciones de salud oral al despertar y tras períodos de fonación prolongada.

Efectivamente, al despertar, la concentración oral de gases sulfurados volátiles resulta mayor debido a la disminución del flujo salival durante el sueño, con la consiguiente reducción del equilibrio bioquímico y de la actividad de autolimpieza bucal y el correspondiente incremento de la actividad putrefactiva bacteriana $(1,38)$. Factores adicionales que agravan este trastorno son la respiración oral -o predominantemente oral- y la frecuente reducción de la humedad atmosférica en los ambientes domésticos, más acentuada en los meses de invierno debido al funcionamiento de las instalaciones de calefacción.

También resulta importante la frecuencia de las comidas, ya que antes y después de éstas se estimula el aumento del flujo salival, y los movimientos mas- 
ticatorios y la fricción del bolo alimenticio permiten el alejamiento y la autolimpieza de los sustratos alimenticios.

Cabe recordar también que si no se realizan las convenientes maniobras de higiene oral, se incrementará, debido a la mayor disposición de nutrientes proteicos que contienen aminoácidos sulfurados, el metabolismo bacteriano. Por consiguiente, durante el período de ayuno sucesivo a la comida se acentúa la volatilización de los compuestos que generan halitosis (1).

\section{Fuentes alimentarias}

Como queda dicho, la cavidad oral está colonizada por más de 600 especies bacterianas (35), muchas de las cuales están capacitadas para degradar proteínas, péptidos y aminoácidos. Cada una de dichas especies ha desarrollado una estrategia diferente con el fin de sobrevivir en un medio ambiente tan competitivo como el oral, ya que si todas las bacterias utilizaran los mismos nutrientes sólo sobrevivirían las más eficaces. La complejidad de la microbiota oral se debe, pues, tanto a la disponibilidad de nutrientes extremadamente diferentes como a la capacidad de muchos microorganismos de degradar incluso sustratos presentes en pequeñas cantidades (1). La presencia de sustratos alimenticios abundantes determina, por lo tanto, el aumento de las poblaciones bacterianas capaces de metabolizar dichos sustratos: por ejemplo, una ingestión elevada de alimentos proteicos que contengan aminoácidos sulfurados, como es el caso de las carnes, los huevos, la leche y los productos queseros, puede proporcionar en mayor medida las fuentes y los sustratos principales para el metabolismo bacteriano putrefactivo $(1,27)$.

Sentado esto, resulta fácilmente comprensible la secuencia de eventos que determina la producción continua de compuestos volátiles de sulfuro, ácidos grasos y poliaminas: la presencia constante de restos abundantes de nutrientes en pacientes con higiene oral escasa provoca la multiplicación de las bacterias, con la consiguiente respuesta inflamatoria. El sangrado concomitante proporciona a su vez un rico sustrato para las especies bacterianas implicadas en la producción de mal olor; contemporáneamente, esta alteración del ecosistema bucal genera una nue- va respuesta inflamatoria, que siguiendo un círculo vicioso aporta a su vez nuevos nutrientes a las poblaciones bacterianas.

\section{Gingivitis y periodontitis}

La detección de microorganismos periodontales gramnegativos anaerobios en las biopelículas linguales de sujetos aquejados de halitosis -por ejemplo, Treponema denticola, Porphyromonas gingivalis, Bacteroides forsythus, Prevotella y Selenomonas-, y la demostración de su actividad como productores de CVS hacen razonable concebir la halitosis como uno de los síntomas asociados a las gingivitis $\mathrm{y}$ a las periodontitis (1).

No obstante, las pruebas actuales acerca del papel predominante de la enfermedad periodontal en la génesis de la halitosis resultan equívocas: tal y como se ha visto en relación con el cubrimiento lingual, muchos autores $(4,21,28,33,35)$ están convencidos de que la mayor producción de mal olor se origina en el dorso de la lengua.

Aunque varios estudios han detectado niveles más elevados de CVS en pacientes con enfermedad periodontal y, en algunos casos, han correlacionado tales niveles con la presencia de bolsas de más de 3 o $4 \mathrm{~mm}(16,24,34,47)$, no se ha tomado en consideración la presencia de cubrimiento lingual, que, como queda dicho, en los sujetos con periodontopatía resulta seis veces más consistente que en los sujetos sin ella (28).

No cabe duda, sin embargo, de que las condiciones que propician la producción de mal olor pueden incrementarse en pacientes con enfermedad periodontal, sujetos en los que aumenta, de hecho, la población microbiana gramnegativa y se da una mayor presencia de sustratos proteicos procedentes del sangrado gingival y del fluido crevicular (18).

\section{Efecto de los CVS en el periodonto}

El sulfuro de hidrógeno y el metilmercaptano, principales compuestos volátiles de sulfuro responsables de la producción de mal olor, también podrían des- 
empeñar un importante papel en la patogénesis de la enfermedad periodontal.

Al exponer la mucosa sublingual a estos dos compuestos, se ha detectado un aumento de la permeabilidad tisular del $75 \%$ y del $103 \%$ respectivamente. Esta mayor permeabilidad podría facilitar la penetración de antígenos bacterianos como los lipopolisacáridos (LPS), induciendo una respuesta inflamatoria.

Los CVS también pueden provocar destrucción tisular debido a su toxicidad para con las células epiteliales, así como alterar la síntesis y el metabolismo proteicos. Johnson et al., citados por Morita y colaboradores (24), pusieron de relieve que la exposición de cultivos de fibroblastos a metilmercaptano y sulfuro de hidrógeno provocaba una reducción del 39\% en la síntesis de colágeno y un incremento del $62 \%$ en la destrucción de las proteínas recién sintetizadas, así como disminución de la síntesis de ADN y alteración del metabolismo de las proteínas colágenas. Efectivamente, ambos compuestos reaccionan con las proteínas a través de los grupos tioles (-SH) y, en combinación con el colágeno tipo I, alteran la funcionalidad de éste.

El metilmercaptano estimula además la producción de interleuquina-1, una citoquina proinflamatoria que induce a los fibroblastos a secretar las prostaglandinas E2, responsables de la destrucción periodontal (24).

En síntesis, los compuestos volátiles de sulfuro responsables de la halitosis podrían desempeñar una función patógena favorecedora de la aparición de la patología periodontal (1). En efecto, al incrementar la permeabilidad de la mucosa (27), pueden penetrar en los tejidos orales y causar lesiones patológicas $(24,27,39)$, modificando el metabolismo celular, la síntesis y la degradación del colágeno. También estimulan los CVS la producción de citoquinas proinflamatorias como la IL-1, responsables de la inducción de fenómenos de reabsorción ósea mediada por las prostaglandinas E2 $(1,18,27)$.

\section{Condiciones patológicas orales}

Todas las situaciones en las que tiene lugar una variación del ecosistema bucal, con incremento o se- lección de las especies bacterianas que pueden producir compuestos malolientes, constituyen una causa común de halitosis acentuada $(1,26)$. Los pacientes aquejados de gingivitis, periodontitis, infecciones odontógenas y no odontógenas de los tejidos blandos - tanto agudas como crónicas-, estomatitis ulcerativas o bullosas —análogamente, tanto agudas como crónicas-, candidiasis agudas, eritema oral multiforme, gingivoestomatitis herpéticas y gingivitis ulcerativa necrosante aguda, suelen presentar una halitosis persistente de intensidad variable $(1,2,13,14,17,40,41)$.

En los pacientes que padecen neoplasias malignas vegetantes y/o ulceradas de la cavidad oral, la halitosis se debe principalmente a la retención de restos alimenticios y a la presencia de tejido necrótico, con la consiguiente acentuación del metabolismo proteico bacteriano: de ello se deduce que la condición patológica conocida como "lengua fisurada o escrotal" — sobre todo en las formas que presentan fisuras particularmente profundas- es determinante en la génesis de la halitosis, ya que con mucha facilidad los restos alimenticios que quedan retenidos en los pliegues tienden a fermentar, produciendo compuestos volátiles.

Además, durante el período postoperatorio sucesivo a intervenciones quirúrgicas intrabucales, todos los pacientes pueden presentar halitosis acentuada si no se adoptan medidas adecuadas de limpieza de las heridas y de control de la superinfección de éstas por parte de los microorganismos de las biopelículas bucales (1).

\section{Higiene oral y factores iatrógenos que favorecen la acumulación de placa}

Una higiene oral escasa, al igual que todas las situaciones iatrógenas que favorecen el estancamiento y la retención de la placa bacteriana y de restos orgánicos y alimenticios - como es el caso de restauraciones incongruentes sin respeto del punto de contacto o del perfil anatómico de los elementos dentales, o con las superficies de los materiales de restauración no adecuadamente alisadas-, constituyen por lo tanto factores que favorecen la aparición de halitosis $(1,4,13,17,29,41)$. 
Un análisis separado lo merece la consideración del papel de las prótesis parciales o totales removibles. En un estudio realizado por Goldberg y colaboradores (42), en una muestra de sujetos portadores de prótesis total removible se detectó la presencia de microorganismos pertenecientes a la familia Enterobacteriaceae en el ecosistema bucal; tales formas microbianas no se corresponden con la flora común de la cavidad oral, pero presentan una gran afinidad de unión con el material acrílico de los aparatos protésicos. Se trata de bacterias que pueden provocar la reducción de compuestos malolientes en el cultivo in vitro: de ahí la hipótesis de que puedan ser corresponsables de la génesis de la "halitosis de origen protésico" $(1,43)$.

Por regla general, el olor generado por las prótesis, especialmente cuando también se mantienen colocadas por la noche, es dulce pero desagradable (42), y resulta fácilmente identificable al introducirlas en una bolsa de plástico cerrada durante unos minutos (8).

\section{BIBLIOGRAFÍA}

1. Abati S. Alitosi. Eziopatogenesi, diagnosi e trattamento. Milano: Ed. Masson; 2001.

2. Scully C, El-Maaytah M, Porter SR. Breath odor: etiopathogenesis, assessment and managernent. Eurj Oral Sci 1997;105:287-93.

3. Miyazaki H, Sakao S, Katoh Y, Takehara T. Correlation between votatile sulphur compound and certain oral health. measurements in the general population. J Periodontol 1995;66:679-84.

4. Loesche WJ, Kazor C. Microbiology and treatment of halitosis. 2000 Periodontol 28:25679.

5. Eli I, Bath R, Koriat H, Rosemberg M. Selfperception of breath odor. J Am Dent Assoc 2001 May;132:621-6.

6. Söder B, Johansson B, Söder PO. The relation between foetor ex ore, oral hygiene and periodontal disease. Swed Dent J 2000;24:73-82.
7. Loesche WJ. The effect of antimicrobiat mouthrinses on oral matodor and their status relative to US Food and Drug Administration regulations. Quintessence Int 1999 May;30: 311-8.

8. Rosemberg M. Clinical assessment of bad breath: current concepts. J Am Dent Assoc 1996 Apr; 127:475-82.

9. Neiders M, Ramos B. Operation of bad breath clinics. Quintessence Int 1999;30:295-301.

10. Delanghe G, Ghyselen MD, Bollen C et al. An inventory of patients' response to treatment at a multidisciplinary breath odor clinic. Quintessence Int 1999;30:307-10.

11. Rösing CK, Jonski G, Rolla. Comparative analysis of some mouthrinses on the production of volatile sulfur-containig compounds. Acta Odontol Scand 2002;60:10-2.

12. Sterer $N$, Greenstein $R$, Rosemberg $M$. Galactosidase activity in saliva is associated with oral malodor. J Dent Res 2002;81(3):182-5.

13. Touyz L. Oral malodor: a scientific perspective. Can Dent Assoc 1993;S9:607-10.

14. Lenton P, Majerus G, Bakdash B. Counseting and treating bad breath patients: a step by step approach. J Contemp Dent Pract 2001;2(2):46-61.

15. Frascella J, Gilbert RD, Fernandez P, Hendler J. Efficacy of a chlorine dioxide containing mouthrinse in oral malodor. Compend Contin Educ Dent 2000;21(3):241-6.

16. Fischman SL. Over the counter mouthrinses. J Calif Dent Assoc 1998;26(3):204-6.

17. Greenstein RB, Goldberg S, Cohen S, Sterer N, Rosemberg M. Reduction of oral malodor by oxidizing lozenges. J Periodontol 1997;68:1176-81.

18. Sánz M, Roldan S, Herrera D. Fundamentals of breath malodour. J Contemp Dent Pract 2001; $4(2): 1-17$. 
19. Quirynen M, Mongardini C, van Steenberghe D. The effect of a 1-stage full-mouth disinfection on oral malodor and microbial colonization of the tongue in periodontitis patients. A pilot study. J Periodontol 1998;69:374-82.

20. ADA council on scientific affair. Oral malodor. J Am Dent Assoc 2003;134(2):209-14.

21. De Boever EH, Loesche WJ. Assesing the contribution of anaerobic microflora of the tongue to oral malodor. J Am Dent Assoc 1995, 126:1384-93.

22. Ratcliff PA, Johnson PW. The relationship between oral malodor, gingivitis and periodontitis. J Periodontol 1999;70:458-89.

23. Seeman R, Kison A, Bizhang M, Zimmer S. Effectivness of mechanical tongue cleaning on oral levels of volatile sulfur compounds, J Am Dent Assoc 2001;132:1263-7.

24. Morita M, Wang HL. Association between oral malodor and adult periodontitis: a review. J Clin Periodontol 2001;28:813-9.

25. Kleinberg I, Codipilly M. Modeling the oral malodor system and method of analysis. Quintessence Int 1999;30:357-69.

26. Shimura M, Qwatanabe S, lwakura $M$ et al. Correlation between measurements using a new halitosis monitor and organoleptic assessment. J Periodontol 1997;68:1182-5.

27. Wåler SM. On the transformation of sulfurcontainig amino acids and peptides to volatile sulfur compounds (VSC. in the human mouth. Eur J Oral Sci 1997;105:534-7.

28. Tonzetich J. Production and origin of oral malodor: a review of mechanism and method of analysis. J Periodontol 1977;48(1):13-20.

29. Ritcher JL. Diagnosis and treatment of halitosis. Compend Contin Educ Dent 17(4):37086.
30. Pera P, Genovesi AM, Romano L, Nardi G. Alitosi: un problema orate diffuso. Prevenzione e assistenza dentale 2000;4:20-4.

31. Nachnani S. Oral malodor: a detailed review. CHDA Jounal 1999.

32. Moss SJ. Halitosis and oral malodor. Report submitted to the FDI Commission 1998;maggio:1-6.

33. Bosy A, Kulkarni GV, Rosemberg M, McCulloch CA, Relationship of oral malodor to periodontitis: evidence of independence in discrete subpopulations. J Periodontol;65:37-46.

34. Reigewirtz Y, Girault O, Reingewirtz N, Senger B, Tenebaum $\mathrm{H}$. Mechanical effects and volatile sulfur compound reducing effects of chewing gums: comparison between test and base gums and a control goup. Quintessence Int 1999; 30:319-23.

35. Kazor CE, Mitchell PM, Lee AM, Stokes LN, Loesche WJ, Dewhirst E, Paster BJ. Diversity of bacterial populations on the tongue dorsa of patients with halitosis and healthy patients. J Clin Microb 2003;41(2):558-63.

36. Yaegaki K, Sanada K. Biochemical and clinical factors influencing oral malodor in pariodontal patients. J Periodontol 1992;63:783-9.

37. Rosenberg M Kulkarni GV, Bosy A. McCulloch CA. Reproducibility and sensitivity of oral malodor measurements with a portable sulfide monitor. J Dent Res 1991;70:1436-40.

38. Kleinberg I. Westbay M. Salivary and metabolic factors involved in oral malodor formation. $\mathrm{J}$ Periodontol 1992;63(9):768-75.

39. Figueiredo LC, Rosetti EP, Marcantonio E, Rosemary A, Salvador SL. The relationship of oral malodor in patients with or wlthout periodontal disease. J Periodontol 2002;73:1338-42.

40. Tonzetich J. Oral malodour: an indicator of health status and oral cleanliness. Int Dent 1978; 28(3):309-19. 
41. Kozlovsky A, Goldberg S, Natour I, Gat A, Rosemberg M. Efficacy of a 2-phase oil water mouthrinse in controlling oral malodor, gingivitis and plaque. J Periodontol 1996;67:577-82.

42. Golberg S, Cardash H, Browning H, Sahly H, Rosenberg M. Isolation of enterobacteriaceae from the mouth and potential association with malodor. J Dent Res 1997;76(11):1770-5.

43. Myatt GJ, Hunt SA, Barlow AP, Winston L, Ashley PB, Bordas A, El Maaytah M. A clinical study to asses the breath protection efficacy of denture adhesive. J Contemp Dent Pract 2002;4(3):1-9.

44. Fornabaio AM, Marziliano P, Scagnetto E, Bocconi S. Lálitosi come problema nella societá moderna: considerazioni e previsioni per il futuro. 1 Congresso Nazionale M Docenti di Odontoiatria. Roma, 24-27 marzo 1994.

45. Preti G, Clark L, Beverly J, Feldman 5, Lowry LD, Weber E, Young IM. Non oral etiologies of oral malodor and altered chemosensation. J Periodontol 1992;63:790-6.

46. Fraccari F, Bogini A, Cocchetto R. Alitosi e foetor ex ore. Stomat Lomb 1988;2(2):295-303.

47. Yaegaki K, Sanada K. Volatile sulfur compounds in mouth air from clinically healthy subjects and patients with periodontital disease. J Periodontal Res 1992;27:233-8.

48. Norfleet RG. Helicobacter halitosis. J Clin Gastroenterol 1993,16:274.

49. The history of professional formulas utilizing stabilized chlorine dioxide for efficacious treatment of bad breath. 4th Internetional Conference on Oral malodor. UCLA School of Dentistry, August 1999.

50. Khaira N, Palmer RM, Wilson RF, Scott DA, Wade WG. Production of volatile sulphur compounds in diseased periodontal pockets is significantly increased in smokers. Oral Disease 2000;6: 371-5.

51. Sharma NC, Galustians HJ, Qaquish J, Galustians A, Rustogi KN, Petrone ME, Chaknis P, Garcia L, Volpe AR, Proskin HM. The clinical effectivness of a dentifrice containing triclosan and a copolymer for controlling breath odor measured organoleptically twelve hours after toothbrushing. J Clin Dent 1999;10:131-4.

52. Yaegaki K, Coil MJ. Examination, classification, and treatment of halitosis; clínical perspectives. J Can Dent Assoc 2000;66:257-61.

53. Yaegaki K, Coil M. Clinical dilemmas posed by patients with psychosomatic halitosis. Quintessence Int 1999;30:328-33.

54. Rosemberg M, Kozlovsky A, Wind Y, Mindel E. Self-assessment of oral malodor 1 year following initial consultation. Quintessence Int 1999; 30:324-7.

55. Lang NP, Attström R, Löe H. Proceedings of the European Workshop on mechanical plaque control. Berne, Switzerland, 9-12 maggio.

56. Rosenberg M, McCulloch CA. Measurement of oral malodor: current methods and future prospects. J Periodontol 1992;63:776-82. 